\title{
Gender Equity Professional Development for Teachers in a Summer Camp Setting
}

\author{
Marion Usselman, Donna Whiting \\ Georgia Institute of Technology
}

The attitudes and classroom behaviors of K-12 teachers can have a substantial impact on whether girls perceive technical careers as appropriate and available to them. It is well documented that elementary girls are enthusiastic in their pursuit of math and science knowledge, but this enthusiasm often declines as the girls reach middle school ${ }^{1}$. Studies of classroom dynamics reveal that teachers often unconsciously interact with girls in ways that discourage active participation and critical thinking about science topics ${ }^{2}$. Professional development for teachers can be an effective tool for raising teachers' awareness about the issues of gender equity, and of classroom equity in general.

Professional development is usually offered in a forum disconnected from the actual classroom, and is often of very short duration. Gender equity workshops that last a matter of hours are only long enough to communicate what the "experts" say, but are not long enough for the true introspection required to change personal behavior. To counter this, the Georgia Institute of Technology, with support from the National Science Foundation ${ }^{3}$ and the Board of Regents of the University System of Georgia, implemented SummerScape: Gender Equitable Science for Students and Teachers. SummerScape was a 2-week "Teaching and Learning" program that consisted of a summer camp for middle school students and a professional development experience for teachers. It was designed to help all students experience confidence and success in science and engineering and to provide teachers with in-depth professional development covering gender equitable science pedagogy and teaching practices. An important component of this teacher experience was the opportunity to practice new teaching strategies immediately following each in-service workshop in a low-risk summer camp environment. This paper will present this "Teaching and Learning Camp" model of teacher professional development, detail the activities covered in the gender equity professional development, and discuss the strengths and weaknesses of the program determined through the project evaluation.

\section{SummerScape Professional Development Format}

For two years 16 middle school teachers per summer were recruited as school teams from MetroAtlanta area school systems. Teachers participated in 6 hours of professional development during the spring semester to provide them with background information about SummerScape, the National Science Education Standards, inquiry-based science, collaborative learning and gender equity. In June SummerScape staff provided 4 days of professional development covering the scientific content for the classes with an emphasis on using inquiry science pedagogical methods. Curriculum units varied each year to accommodate repeating students, but were generally developed or adapted to reflect real-world engineering and science problems and to provide students with the type of hands-on technological experiences girls have often not previously encountered (e.g. using tools such as soldering irons and electric drills, or wiring circuit boards). Examples of curriculum units include: 
- Electricity and Circuits: a curriculum designed by a high school technology teacher that culminated in building and racing a solar powered car.

a Bottle Biology: a commercially available curriculum that emphasizes the creation of life science experiments and activities using recycled plastic bottles.

- Learning by Design: a design-based engineering curriculum created by Dr. Janet Kolodner, Professor, Georgia Tech College of Computing, with support from NSF.

- Civil Engineering and Earthquakes: a civil engineering curriculum designed by a high school technology teacher that culminated with the students creating balsawood towers and testing their strength on an earthquake simulation machine.

a Thinking Like Leonardo: a curriculum created by Dr. Carol Whitescarver, Director of Continuing Education in the Georgia Tech College of Architecture, that entailed designing, constructing, and testing a large chair of heavy cardboard.

\section{Equity Professional Development}

During the two-week summer camp teachers team-taught one curriculum content to two 90minute classes of approximately 20 students per day. There were approximately equal numbers of girls and boys in the camp, and they were grouped for one class as a single-sex class, and for the other they were combined in co-ed groups. An integral component in the professional development was giving the teachers the opportunity to observe and manage children in different types of gender groupings, and to discuss the results during the gender equity workshops.

During the two-week equity professional development experience, teachers participated in daily 90-minute workshops covering a wide range of gender equity and basic classroom equity issues. Teachers were asked to note differences in the environment or classroom climate between single sex and co-ed classes and groupings. These differences, as well as classroom management strategies for addressing equity problems, were discussed extensively during the professional development time. As the workshop evolved, the emphasis turned to the Equitable Classroom in general, stressing the connection between gender equity and the larger classroom equity issues dealing with race, socioeconomic level, and perceived achievement potential.

\section{Professional Development Activities and Resources}

Activities and resources were drawn from a variety of sources. Many are reproduced in the InGEAR Professional Development Manual for Gender Equity in Collegiate Science, Engineering, Mathematics, and Education, developed in Georgia with support from $\mathrm{NSF}^{4}$ and available online at http://www.ceismc.gatech.edu/ceismc/programs/ingear/homepg.htm. The level of instruction and exact set of activities used with any group of teachers depended upon the beginning awareness level of the teachers and their willingness to engage in self-evaluation and reflection. Some teachers were highly knowledgeable about gender issues and looked upon the program as an advanced workshop in the field, and some teachers entered the program completely ignorant about the topic. Independent of the beginning awareness level, some teachers were much more willing to reflect upon their own behavior than others were, and to honestly engage in a class dialog.

The materials, resources, topics and activities included in the SummerScape professional development workshops are listed below. 
$\underline{\text { Print Materials }}$

- Classroom Strategies for Gender Equity.

Weinburgh, Molly. InGEAR Professional Development Manual, (1999) pg. 72

- Examples of Non-biased, Inclusive Language.

Adapted from Crawford, S.H. (1996) ${ }^{5}$. Included in InGEAR Professional Development Manual, (1999) pg. 76

- Differential Treatment of Women and Men.

Adapted from Sandler, B.R. \& Hoffman, E. (1992) ${ }^{6}$ included in InGEAR Professional

Development Manual, (1999) pg. 88

- InGEAR's Tips for Designing an Equitable Science or Mathematics Course. InGEAR Professional Development Manual, (1999) pg. 103

- Guidelines for Evaluating Science Books for Stereotyping and Bias. Compiled by Hulme, M.A? . Included in InGEAR Professional Development Manual, (1999) pg. 113

- Guidelines for Evaluating Mathematics Books for Stereotyping and Bias. Compiled by Hulme, M.A. Included in InGEAR Professional Development Manual, (1999) pg. 115

- Why Me? Why My Classroom? The Need for Equity in Coed Math and Science Classes.

Campbell, P.B. \& Storo, J.N. Office of Educational Research and Improvement, U.S. Department of Education. (1994) Available at http://www.campbell-kibler.com/

- Girls Are... Boys Are...: Myths, Stereotypes \& Gender Differences

Campbell, P.B. \& Storo, J.N. Office of Educational Research and Improvement, U.S. Department of Education. (1994) Available at http://www.campbell-kibler.com/

- Whose Responsibility Is It? Making Coeducation Work in Math \& Science: The Administrator's Role.

Campbell, P.B. \& Storo, J.N. Office of Educational Research and Improvement, U.S. Department of Education. (1994) Available at http://www.campbell-kibler.com/

- Making It Happen: Pizza Parties, Chemistry Goddesses and Other Strategies that Work for Girls and Others.

Campbell, P.B. \& Storo, J.N. Office of Educational Research and Improvement, U.S. Department of Education. (1994) Available at http://www.campbell-kibler.com/

- Profile of an Equitable Math and Science Classroom and Teacher. Wallace, J. Vermont Institute for Science, Mathematics and Technology. (1993)

- Gender Gaps: Where Schools Still Fail Our Children.

American Association of University Women (1998)

- Articles pulled from current newspapers, journals, and magazines.

Video Resources

- Failing at Fairness

Two videos from the Dateline NBC. (1994)

- Girls Can!

American Association of University Women (1995)

- Girls in the Middle: Working to Succeed in School

American Association of University Women (1996) 
- Gender Equity in the Classroom: For Educators K-12, Pre-Service Programs and Staff Development. Hosted by David Sadker. Distributed by Great Plains National. (1998)

Gender Equity Activities

- Famous Women and Men InGEAR Professional Development Manual, (1999) pg. 80

- Is my classroom equitable? A self-awareness reflection.

- Growing up the opposite sex. A self-awareness reflection.

- Gender and Science Inventory Weinburgh, M.H., Franklin, B. \& Franklin, C. (1994) ${ }^{8}$ Included in the InGEAR Professional Development Manual, (1999) pg. 78

- Accomplished Women in Science and Mathematics. InGEAR Professional Development Manual, (1999) pg. 83

- What is your Gender Awareness Quotient (GAO)? Adapted from Sadker, M., Sadker, D. \& Kaser, J. $(1985)^{9}$, included in the InGEAR Professional Development Manual, (1999) pg. 84

- The Equitable School Walk. Source: Nation's Regional Educational Laboratories ${ }^{10}$ (1992). Included in the InGEAR Professional Development Manual, (1999) pg. 106

- Equity Reality Check: A School Rating. Adapted from Science Education Reform for All. AAAS, (1996). Included in the InGEAR Professional Development Manual, (1999) pg. 109

- Gender Audit of Physical Classroom Adapted from Science Education Reform for All. AAAS, (1996). Included in the InGEAR Professional Development Manual, (1999) pg. 112

- Classroom Observations for Teacher/Student Interactions Adapted from Sadker, Sadker, Bauchner, and Hergert. Included in the InGEAR Professional Development Manual, (1999) pg. 90

- SummerScape Faculty-Student Interaction Observation Sheet. Created by SummerScape staff for classroom coding exercises. Available on request from marion.usselman@ ceismc.gatech.edu.

Other Topics Discussed

- National Science Education Standards ${ }^{11}$

- Instructional models for lesson organization.

- Visual organizers

- Alternative Assessment

- Cooperative Learning

- Learning Styles/Multiple Intelligences

- Action Research

\section{School Year Component}

During the school year teachers were asked to

- Conduct a gender equity workshop for the staff at their school, 
- Identify a problem or question related to gender equity that they wanted to pursue or investigate at their school using action research, and to implement their plan,

- Return to Georgia Tech for periodic SummerScape meetings, and

- Submit a written report detailing their activities and modified lesson plans.

Teachers were also encouraged to observe each other periodically in the classroom to check on their progress in providing equitable attention to all students, and to conduct a gender equity workshop for parents at their school.

\section{Online Community}

All professional development materials and teacher final reports were posted online on a SummerScape WebCT course. The classroom instruments and activities were all available as pdf files on the course.

\section{Teacher Compensation}

Teachers received \$1,250 and 10 Staff Development Units as compensation for the full year SummerScape program, half paid at the end of the camp session, and the remainder the following spring when they had completed the school-year component on SummerScape. To support these school-year efforts, SummerScape offered to provided money to pay for a substitute teacher for two release days per teacher, $\$ 100$ worth of gender equitable resource materials per teacher, and \$100 to support the school-year gender equity workshops.

\section{Evaluation of Professional Development Model}

All professional development workshops carry the burden of demonstrating that the experiences have had the desired results. This is notoriously difficult given that the ultimate goal of virtually all teacher professional development is an increase in student learning and achievement. This quantitative goal is nearly impossible to definitively demonstrate when working with small groups of teachers who attend summer professional development workshops. Instead, staff developers usually rely on evaluating whether teachers liked the workshop, and less frequently, whether they actually learned the material that was presented. SummerScape's professional development, which primarily addressed the general topic of classroom equity, and the more specific issue of gender equity, is even harder to evaluate than traditional workshops that cover discrete content material, curriculum activities, or classroom management techniques. Much of the material covered during the SummerScape in-service workshops dealt with awareness raising and self-reflection. It is a challenge for professional development staff to truly evaluate this type of experience, since even if participants can successfully regurgitate the national data on gender equity, it doesn't mean that they have necessarily internalized the message or will change behaviors in the classroom. As an added complication, teachers enrolled in SummerScape with widely varying pre-existing levels of understanding and appreciation of the topic. The goal of the in-service therefore had to be to move all teachers up to a higher "level of awareness", but that final level might be different for all participants.

To aid in judging teacher progression, we developed the general levels of teacher awareness and concern indicated in Table 1. This scale parallels other scales that describe, for instance, multiple "Stages of Concern" regarding school improvement efforts such as those advocated by the National Staff Development Council. ${ }^{12}$ 


\begin{tabular}{|l|l|l|}
\hline \multicolumn{3}{|c|}{ SummerScape Scale of Teacher Awareness and Concern } \\
\hline Level & Descriptor & Description \\
\hline 4 & Director & $\begin{array}{l}\text { Actively acts as agent for } \\
\text { school/district change }\end{array}$ \\
\hline 3 & Modifier & $\begin{array}{l}\text { Actively monitors own behavior, } \\
\text { changes individual classroom practice. }\end{array}$ \\
\hline 2 & Reflector & $\begin{array}{l}\text { Applies awareness to self, reflects on } \\
\text { own behavior. }\end{array}$ \\
\hline 1 & Attender & $\begin{array}{l}\text { Awareness of literature, national } \\
\text { statistics, what "experts" say. }\end{array}$ \\
\hline 0 & Unaware & Negligible awareness of topic \\
\hline
\end{tabular}

We attempted to rate teacher progress on the Scale of Teacher Awareness and Concern at the end of the full-year SummerScape program. This evaluation was based in large part on the results of the school-year component of the program. Teachers who returned to their schools, implemented action research projects, and conducted well thought-out gender equity workshops for their colleagues were judged to be on a higher level of concern than those who gave what might be considered to be lip service to the school year requirement. This assessment, when combined with evaluation survey results and recorded teacher comments, forms the basis for our evaluation of our model of professional development.

\section{Quality of Summer Program Professional Development}

\section{Evaluation Survey Results}

Teacher participants were asked to evaluate the summer program utilizing a Likert scale questionnaire and short answer questions. Overall, the quality of the professional development activities received an average score of 4.24. The uniqueness and innovation of the professional development activities received the highest rating (4.52) and the adaptation of the program schedule to participants needs received the lowest (3.90). A summary of professional development ratings can be found in Table 2 .

The teacher evaluations at the end of the summer session of SummerScape included room for open-ended comments regarding the program. Samples of these comments are included in Table 3. When appropriate, the comments are placed into groups indicating which level of awareness on the SummerScape Scale of Teacher Awareness and Concern is suggested by the comment. The majority of comments indicated a Level 1 Concern, namely an awareness of the literature, the national statistics, and what the "experts" say. Some comments suggested a deeper integration of the material by the teacher, and an expectation that the teacher would actively use the material in his or her classroom. These comments were grouped as Level 2 and Level 3 Concern. Regardless of the apparent level of the comments, virtually all teachers reported a definite increase in their level of gender equity awareness. When asked to rate their pre- and post-SummerScape awareness level of issues of gender equity, 27 of 29 respondents rated their post-SummerScape awareness level as substantially higher than their pre-SummerScape awareness level. The remaining two participants rated their pre-SummerScape awareness level to already be very high. 


\begin{tabular}{|c|c|c|c|c|c|c|}
\hline & $\begin{array}{l}\text { Strongly } \\
\text { Agree } \\
5\end{array}$ & $\begin{array}{c}\text { Agree } \\
4\end{array}$ & $\begin{array}{c}\text { Un- } \\
\text { decided } \\
3\end{array}$ & $\begin{array}{c}\text { Disagree } \\
2\end{array}$ & $\begin{array}{l}\text { Strongly } \\
\text { Disagree } \\
1\end{array}$ & Average \\
\hline $\begin{array}{l}\text { SummerScape had some outstanding } \\
\text { components that were unique or innovative. }\end{array}$ & 18 & 11 & 2 & 0 & 0 & 4.52 \\
\hline Presentations were well organized. & 6 & 21 & 3 & 0 & 1 & 4.00 \\
\hline $\begin{array}{l}\text { The program schedule was well adapted to my } \\
\text { educational needs. }\end{array}$ & 5 & 19 & 3 & 1 & 1 & 3.90 \\
\hline $\begin{array}{l}\text { The strategies utilized, including instructional } \\
\text { resources, were appropriate for meeting the } \\
\text { stated objectives. }\end{array}$ & 12 & 14 & 3 & 1 & 1 & 4.13 \\
\hline $\begin{array}{l}\text { Overall, personnel conducting the activity } \\
\text { exhibited the qualities essential to the success } \\
\text { of the workshop. }\end{array}$ & 14 & 14 & 3 & 0 & 0 & 4.35 \\
\hline $\begin{array}{l}\text { Overall, SummerScape was a successful } \\
\text { training experience for me. }\end{array}$ & 16 & 12 & 3 & 0 & 0 & 4.42 \\
\hline $\begin{array}{l}\text { Adequate provisions were made for me to } \\
\text { identify needs that were not previously } \\
\text { identified. }\end{array}$ & 12 & 15 & 3 & 0 & 0 & 4.30 \\
\hline Workshop objectives were presented clearly. & 11 & 16 & 4 & 0 & 0 & 4.23 \\
\hline $\begin{array}{l}\text { Adequate time and structure were provided for } \\
\text { reflection. }\end{array}$ & 15 & 12 & 2 & 1 & 1 & 4.26 \\
\hline $\begin{array}{l}\text { The design of the staff development activities } \\
\text { encouraged a collaborative approach. }\end{array}$ & 14 & 14 & 2 & 0 & 1 & 4.29 \\
\hline
\end{tabular}

\begin{tabular}{|c|c|}
\hline \multicolumn{2}{|c|}{ Table 3-- What were the most important things you learned through the SummerScape } \\
experience?
\end{tabular}




\section{Program Improvement Suggestions}

Most suggestions for program improvement dealt with technical aspects of running the campmaking sure all the materials and supplies were there, ensuring teachers were paid on time, etc. When we asked specifically about the gender equity professional development, we found that while there were a few teachers who would have preferred a shorter experience, most of the teachers were highly enthusiastic and asked specifically for additional materials and activities. In addition, most of the evaluations of the summer component of SummerScape were very positive, indicating that the vast majority of the participating teachers felt that they had learned a large amount of material and anticipated using the materials in the classroom. However material learned in summer professional development programs is often never implemented into the actual classroom. Therefore SummerScape included a school-year component intended to encourage teachers to bring the material from the summer program back into their schools and classrooms.

\section{School-Year Implementation}

The SummerScape program required that teachers return to their schools and conduct a gender equity workshop for their school staff, and implement a gender-related action research project at the school. To support the workshops we provided each teacher with $\$ 100$ to purchase resource materials from a list that we had compiled, and offered each school team $\$ 100$ to pay for materials and supplies for their gender equity workshop. In addition, we posted all of the course print materials on the program's WebCT page, and made available copies of all videotapes used in the course. The effectiveness of the teachers' workshop efforts varied tremendously, from multiple presentations to over 100 teachers, to small presentations before individual teaching teams, to no presentations at all.

Action research projects can be particularly important in helping teachers internalize the materials, in convincing school peers of the need for change, and in ultimately effecting change within the classroom and school. To encourage serious research projects we offered to pay for substitutes for two days of release time so the teachers could conduct their action research projects. However very few schools invoiced us for either the workshop materials and supplies or the release time substitutes, though all teachers placed their personal orders for the resource materials. Evidently many schools are not well versed in the process of invoicing external institutions for money, and/or it is considered more trouble than it is worth. In addition, there is a severe shortage of qualified substitute teachers, so few of the SummerScape teachers actually took any release days.

\section{Year 1}

During Year 1, there were six schools represented during the summer. The teacher-teams from four of these schools successfully completed the SummerScape program by conducting gender equity workshops for their school staff, and conducting small projects at the school. However none of the projects really qualified as an action research project, since none of the teachers actually collected and analyzed any data. During Year 2 we modified the summer program to include more information on how to conduct an action research project, which greatly improved the action research component of the school-year program. The final two schools during Year 1 had much less success during the school year. All four teachers from one school left the school in the fall. Two of the teachers stayed in touch with the SummerScape staff. One, who became a counselor at an elementary school, successfully implemented the SummerScape material into 
workshops for PTA presidents and for teachers at her new school. Although she didn't conduct a research project, she produced materials for distribution to various audiences. The other teacher attempted to implement the materials at her new school, but was only successful in bringing the material to a small number of teachers and students. The other two teachers from that school were never heard from again, and were not paid the second half of the SummerScape stipend. The two teachers from the sixth Year 1 school were also not successful in implementing the school-year component of SummerScape. The reasons for this are an important component of our lessons learned, and are discussed later.

\section{$\underline{\text { Year } 2}$}

During Year 2, SummerScape had teachers from 11 different schools, with five teams consisting of two teachers each plus six teachers participating as solo individuals from their school. Two of the teams and one individual conducted excellent school-year projects. In each of these cases the teachers visited numerous classrooms in their school and in neighboring schools and gathered data using the SummerScape Faculty-Student Interaction Observation Sheet. In most classrooms it was clear after even a short observation that the boys were receiving more teacher-student interactions than the girls, thus validating the materials presented in SummerScape. This action research experience served to make "true believers" out of those teachers and they actively acted as agents for school/district change. These SummerScape teachers presented their individual coding results to the observed teachers and the total consolidated results at their gender equity staff meetings, thereby deflecting criticism from their peers that the national data didn't apply to their school. They then became active and effective gender equity promoters within their schools. It is worth mentioning that one of these teams consisted of two African-American men from a primarily African-American school who initially signed up for SummerScape without any idea of what the program was about, and were totally ignorant about the subject. However they were perfect examples of teachers who, given time, were willing to openly reflect upon their own ideas and behaviors, and who, in the end, were thoroughly convinced by their own school research. One additional team observed teachers and surveyed students in their school however this team showed little inclination to initiate change in the school.

\section{Scale of Teacher Awareness and Concern}

At the conclusion of the SummerScape experience we attempted to assessed what level of teacher awareness and concern was evident in each teacher or teacher-team by the end of the school-year component of SummerScape. Because of the intensity, duration, and reflective nature of the SummerScape professional development in-service, most teachers reached Level 2 ("Reflector-Applies awareness to self, reflects on own behavior.") during the summer program. Their final comments generally indicated an appreciation of the self-reflective nature of the issues of equity. Three teachers in Year 2 only reached Level 1 (Attender-Awareness of literature, national statistics, what "experts" say"), despite all the self-reflective activities included in the curriculum. These three resisted the material throughout the summer and showed little evidence that they were willing to even contemplate how their own behaviors influenced classroom equity. However since these three all definitely started at Level 0 ("Unaware-Negligible awareness of topic"), even they moved forward a little.

It is impossible to determine how many of the teachers who we judged to be at Level 2 actually moved along to Level 3 ("Modifier-Actively monitors own behavior, changes individual 
classroom practice") during the school year. We placed four teachers in the Level 3 category because their school-year projects suggested that they were implementing change, but not necessarily at the whole school level. However we did not have the funds to finance extensive classroom visits during the year, a program component that would have better established how much classroom implementation was occurring among the teachers.

The school-year requirement that teachers conduct a gender equity workshop and an action research project was a powerful tool to help teachers move up to Level 4 ("Director-Actively acts as agent for school/district change"), and to document that change. Based on their schoolyear activities, we deemed that 11 of the 32 teachers had moved up to the level of being a schoolhouse leader in the realm of classroom equity. Other teachers conducted gender equity workshops and small projects, but only those 11 showed evidence of impacting a significant number of people at their school. Some of the teachers who finished at Level 4 began the experience at Level 0 . Others began at higher levels of prior knowledge and awareness, but we did not conduct any diagnostic activities to determine the entry level.

\begin{tabular}{|c|c|c|c|}
\hline $\begin{array}{c}\text { \# of } \\
\text { Teachers }\end{array}$ & Level & Descriptor & Description \\
\hline 11 & 4 & Director & $\begin{array}{l}\text { Actively acts as agent for } \\
\text { school/district change }\end{array}$ \\
\hline 4 & 3 & Modifier & $\begin{array}{l}\text { Actively monitors own behavior, } \\
\text { changes individual classroom practice. }\end{array}$ \\
\hline 14 & 2 & Reflector & $\begin{array}{l}\text { Applies awareness to self, reflects on } \\
\text { own behavior. }\end{array}$ \\
\hline 3 & 1 & Attender & $\begin{array}{l}\text { Awareness of literature, national } \\
\text { statistics, what "experts" say. }\end{array}$ \\
\hline 0 & 0 & Unaware & Negligible awareness of topic \\
\hline
\end{tabular}

\section{Reasons for poor school-year implementation}

One disturbing element of SummerScape was that a certain number of very able and concerned teachers either paid only lip-service to the school-year component, or disappeared entirely from the program, sacrificing their second paycheck in the process. Though some of them may have successfully transferred gender equitable strategies into their own teaching, they were not able to implement the requirements of the program once the school year started. Since a disproportionate number of these teachers were from high-risk, stressful schools, it is important to explore the reasons for their inability to carry through with the program.

The primary problem appeared to be time--time to actually implement their action research plans, time to plan and conduct a staff development workshop, and time to attend extra meetings at Georgia Tech. Many of these teachers were the primary faculty in their buildings called on by principals to take responsibility for extracurricular activities, including sponsoring clubs, coaching, writing grants and planning programs for students. This was the personal quality that made them sign up for an extensive summer workshop in the first place. However once school started back, they had very little time to complete their SummerScape action plans. Several of 
the participants were also enrolled in graduate school, and their graduate school requirements took precedence over SummerScape activities. Again, when time was minimal, the implementation of gender equitable projects became a low priority. Perhaps with additional support from project staff, including classroom visits, the teacher s could have more successfully implemented the school-year components.

Another factor impacting the success of school level implementation was evidently the low priority given to gender related issues in some of the participants' schools. For example, participants from schools with high (90\% or more) African American populations had more difficulties implementing their school year program than did teachers from primarily Caucasian schools. Since the majority of the high-achieving students in the minority schools were African American girls, the issue of equity for girls was understandably viewed as a low priority issue in these schools. The perception was that since nearly all of the students in the advanced or honors math and science classes were girls, best practices for African American boys were needed instead. SummerScape teachers had difficulty convincing school level faculty, including building administrators, that gender equitable practices benefit all students, not just girls. More information and materials that integrate and are relevant to people of color, including minority males, should have been included in the summer program. Project staff may not have provided enough of these types of tools. Therefore, participants may not have had enough resources to "convince" building staff of the importance of the issue.

Since many of these SummerScape teachers were not the "power brokers" in their buildings, it was easier for them to move forward with priorities set by the school as a whole rather than becoming agents for change. It is important to note that implementation of gender equitable best practices was not a part of any of our participants' school or department plans. In some cases, teachers were selected from schools recommended by system level administrators. Therefore, some of the schools may have felt "forced" to select participants without having ownership of the experience. An alternate selection procedure might be to present the project to all of a school system's building level administrators and let them self-select into the project. This would enable project staff to work with principals, building level planners, and teachers prior to the selection to create project "buy in" and ownership.

\section{SummerScape Professional Development-Conclusions, Strengths, and Weaknesses.}

The evaluation of the SummerScape program shows that the Teaching and Learning Camp can be a very effective model for gender equity teacher professional development. In particular:

- The summer inservice provides enough time for teachers to develop mutual trust and to adequately reflect on themselves and on the school classroom, thereby genuinely raising awareness, alleviating barriers to change, and facilitating changes in classroom behavior. In the process, most teachers rose to at least a Level 2 on the SummerScape Scale of Teacher Awareness and Concern

- The connection with the summer camp provides teachers with the opportunity to immediately try out strategies, analyze classroom dynamics, and modify student groups, leading to additional valuable discussions in the professional development workshop and to a validation of the workshop materials. 
- The establishment of school teams provides teachers with a supportive colleague both during the summer and during the school year implementation. It was the exceptional teachers who were able to successfully implement the materials back in their own school on their own.

a The school-year gender equity staff development workshop solidifies the teachers' understanding of the material when they are required to present it to their peers. It also serves to disseminate the material to a much larger audience, and to promote leadership in teachers.

- The action research project encourages teachers to monitor and change their immediate environment, and provides them with local data to present to their school peers. It is a powerful tool for helping teachers become genuine change agents in their school, and making them Level 4 Directors on the SummerScape Scale of Teacher Awareness and Concern.

Most of the weaknesses of the program pertain to the realities of implementing a program that extends through the school year. The major lessons learned were:

- Teachers are very pressed for time during the school year, and projects that are not related to their everyday responsibilities tend to get pushed to the back burner. Offering to pay for substitute teachers is useful in some cases, but often there is such a shortage of qualified substitutes that teachers are either not allowed to take release time or they feel that their students will be shortchanged if they are absent. Withholding half of the teacher's financial compensation until the end of the school year is an effective means of making sure that he or she will do something, however small, back in their school. However we were reluctant to make the requirements for completion very strict in the end, and all teachers who stayed in touch and sent us any report at all received their checks. Only teachers who we never heard from again were not paid.

- Adequate school year follow-up support by project staff is extremely labor-intensive and therefore very expensive. Strong teachers who teach in lower-risk school settings (i.e. those schools with good leadership, supportive parents, where teachers feel valued as professionals, and where they are not overwhelmed with the responsibilities of the job) are able to implement the school-year component with minimal help from the project staff. However there were definitely teachers in the SummerScape program who would have successfully implemented school-year projects if the project staff had provided more hands-on assistance and emotional support. This should have been built into the program.

- Arranging general meetings with the teachers after school is very difficult because of the time constraints on the teachers. It helps to provide dinner and a room for children.

- There are advantages and necessities to working with school system administrators when identifying schools and teachers for involvement in professional development programs, particularly when the school system is paying for a portion of the teacher stipends. However this can lead to a "top-down" decree that teachers attend, thereby leaving the school-level administrators out of the decision-making loop. For effective school-year implementation, it is absolutely crucial to have support from the school principal.

\footnotetext{
${ }^{1}$ American Association of University Women (1992). How schools shortchange girls: A study of major findings on girls and education. Washington, D.C.: Author.

${ }^{2}$ Sadker, M., \& Sadker, D. (1994) Failing at fairness: How America's schools shortchange girls. New York: Charles Scribners's Sons.
} 
${ }^{3}$ Through NSF grant HRD\#97-11046-SummerScape: Gender Equitable Science for Students and Teachers

${ }^{4}$ Through NSF grant HRD\#94-53106-InGEAR: Integrating Gender Equity and Reform

${ }^{5}$ Crawford, S. H. (1996). Beyond dolls and guns: 101 ways to help children avoid gender bias. Portsmouth, NH: Heinemann.

${ }^{6}$ Sandler, B.R. and Hoffman, E. (1992) Teaching faculty members to be better teachers: A guide to equitable and effective classroom techniques. Washington, D.C.: Project on the Status of Education of Women, Association of American Colleges.

${ }^{7}$ Revised, updated and edited by Marylin A. Hulme, with reference to Non-sexist curricular materials for elementary schools by Laurie Olson Johnson, The Feminist Press, 1974

${ }^{8}$ Weinburgh, M.H., Franklin, B. \& Franklin, C. (1994, Spring). Gender equity in middle school science classrooms. Current Issues in Middle Level Education, 2(1), 11-19

${ }^{9}$ Sadker, M., Sadker, K. and Kaser, J. (1985). The communications gender gap. The Mid-Atlantic Center for Sex Equity, The American University, School of Education, Washington, D.C.

${ }^{10}$ The NETWORK, Inc. (1992) Facilitating systemic change in science and mathematics education: A toolkit for professional developers, Nation's Regional Educational Laboratories. From “The Equitable School Walk".

${ }^{11}$ National Research Council (1996). National Science Education Standards. National Academy Press, Washington, D.C.

${ }^{12}$ RESULTS: National Staff Development Council. April 2001. Adapted from Evaluating Professional Development, California: Corwin Press, 2000

\section{MARION C. USSELMAN}

Dr. Marion Usselman is a Research Scientist at the Center for Education Integrating Science, Mathematics and Computing (CEISMC) at the Georgia Institute of Technology. She received her Ph.D. in Biophysics from Johns Hopkins University and now focuses on issues of equity and science education reform in K-12 education. She was the Principal Investigator for the SummerScape professional development program.

\section{DONNA WHITING}

Ms. Donna Whiting is a Program Manager at the Center for Education Integrating Science, Mathematics and Computing (CEISMC) at the Georgia Institute of Technology. She received her MA in Curriculum and Instruction from the University of Detroit, Mercy and taught middle school in the Atlanta Public Schools. She focuses on the integration of science and technology in education, and was co-PI on the SummerScape project. 